laboratory facilities exist should establish and maintain regular antimicrobial susceptibility surveillance to support local and national STD programmes. The absence of laboratory facilities also prevents microbiological screening of clients seeking intrauterine contraceptive devices (IUCD).

Antibiotic cover is given to IUCD clients to prevent the development of pelvic inflammatory disease. The usefulness of this practice and the implications of drug pressure for the development of antibiotic resistance have not been evaluated.

Lack of adequate funding limits the number of clinicians who can be trained in case management and the frequency with which such training is organised. Training programmes frequently do not cover medical specialists in the public sector or clinicians in the private sector. They are often not problem based or designed to address practical problems such as patient demand and prescriber self interests, and are seldom evaluated. Consequently, they may have little impact on decisions on case management.

Other obstacles to STD control in Ghana are the social stigma attached to the diseases which also influences patient attendance to health facilities and partner notification and management, patient preference for alternative medical care, and the paucity of research. Practices such as female genital mutilation, use of traditional enema syringes in labour wards, as well as the lack of disposable pipettes for drawing capillary blood, etc, and disposable specula for pelvic examinations could increase the risk for HIV transmission.

In order to be more effective control programmes for STDs in developing countries should take account of the prevailing sociocultural environment, be integrated with other primary healthcare activities, be multisectoral, and be supported by relevant epidemiological and health systems research.

WILLIAM K BOSU

London School of Hygiene and Tropical Medicine, Department of Clinical and Laboratory Science, Keppel Street, London WC1E $7 H T$

1 Adler MW. Sexually transmitted diseases control in developing countries. Genitourin Med 1996;72:83-8.

2 Fransen L, van Dam CJ, Piot P. Health policies for controlling AIDS and STD in developing countries. Hlth Pol Plan 1991, 6:148-56.

3 Grosskurth H, Mosha F, Todd J, Mwijarubi E, Klokke A, Senkoro $\mathrm{K}$, et al. Impact of improved treatment of sexually transmitted diseases on HIV infection in rural Tanzania: diseases on Hred infection in rural 346:530-6.

4 Adu-Sarkodie YA, Brown EP. Self-medication in patients attending a STD clinic. International Society for STD Research Conference, New Orleans, August, 1995 Abstract No 092 .

5 Adu-Sarkodie YA. Antimicrobial susceptibility of Neisseria gonorrhoeae in Kumasi. Ghan Med f 1993/94;27-28:529-35.

6 Ministry of Health. Republic of Ghana. Treatment guidelines for middle level facilities. Accra, 1995 .

7 WHO Model Prescribing Information. Drug used in sexually transmitted diseases and HIV infection. Geneva: World Health Organisation, 1995

8 Hanson S, Sunkutu RM, Kamanga J, Hojer B Sandstrom E. STD care in Zambia: an evaluation of the guidelines for case management through a syndromic approach Int $\mathcal{Y}$ STD AIDS 1996;7:324-32.

9 Ofori-Adjei D, Arhinful DK. The effect of training on the clinical management of malaria by medical assistants in Ghana. So Sci Med 1996;42:1169-76.
Screening for sexually transmitted diseases in an HIV testing clinic: uptake and prevalence

We read, with interest, the report from Madge et $a l^{1}$ of their free standing HIV same day testing (SDT) service which has been established outside a genitourinary medicine (GUM) framework. Since December 1993 we have been providing a SDT service within our GUM clinic.

The SDT clinic is open one morning a week at our Victoria site and is staffed by a health adviser. Doctors, nurses, and receptionists are available as required from the concurrent GUM clinic. Individuals are interviewed by the health adviser who records information regarding sexual history, initiates safer sex education, provides information about sexual health in general, discusses the issues surrounding HIV testing for that individual, and informs the person of the full range of sexual health facilities available at the clinic, including STD screening, cervical cytology, family planning, hepatitis B vaccination, and psychosexual therapy. Individuals are strongly encouraged to see a doctor for examination and investigation. If infections are detected they are treated immediately according to standard clinic practice. Results are given by the same health adviser together with post-test discussion to reinforce safer sexual practices and to promote sexual health. Any with positive results are seen by a doctor and continuing medical care is offered. Those having other tests such as hepatitis B serology or STD screening are asked to telephone in 1 week's time for the result.

In the first 4 months of the clinic, 83 individuals, aged 18-51 years, were seen. Eighty two proceeded to HIV SDT. Data on these individuals are presented below.

HIV seropositivity was found in one of 11 homosexual men, one of two bisexual men none of 28 heterosexual men, and none of 42 heterosexual females. One equivocal HIV result was obtained in a heterosexual woman; however subsequent tests were negative.

Previous genital infection was reported in 22 individuals with 36 infections in total.

We concur with Madge et al's findings, not only of a low uptake of STD screening ( $34 \%$ in our cohort), but also of a low prevalence of STDs among the 28 screened (one pelvic inflammatory disease, one non-gonococcal urethritis). This is a lower rate of screening for sexually transmitted disease and of genital infection when compared with people having routine $\mathrm{HIV}$ testing in our GUM clinic. ${ }^{2}$

Thirty three people were tested for hepatitis $\mathrm{B}$, six received hepatitis $\mathrm{B}$ immunisation as a result - an $80 \%$ delivery rate for homosexual men (table). This is more than three times the rate reported by Madge et al and may reflect the ability of GUM clinics to offer immediate immunisation on site rather than offering referral for immunisation.

Over the subsequent year only four of the

\section{Hepatitis $B$}

\begin{tabular}{llll}
\hline & $\begin{array}{l}\text { Number } \\
\text { screened }(n)\end{array}$ & $\begin{array}{l}\text { Found Hep B s ab } \\
+ \text { ve }\end{array}$ & $\begin{array}{l}\text { Subsequently } \\
\text { immunised }\end{array}$ \\
\hline Heterosexual women & $13(42)$ & 0 & 1 \\
Hetersexual men & $7(28)$ & 1 & 1 \\
Homosexual men & $9(11)$ & $3 \star$ & 4 \\
Bisexual men & $2(2)$ & 0 & 0 \\
\hline
\end{tabular}

^An additional homosexual man was found to be Hep B core antibody positive.

83 patients returned for STD screening. Hence, we would caution against Madge and colleagues' suggestion that STD screening could be done at a GUM clinic at a later date.

There is a significantly lower yield of positive HIV results in all risk groups attending this clinic $(2 \cdot 4 \%)$ compared with that identified by unlinked anonymous testing in our GUM clinic or on "routine" HIV testing $(9 \cdot 8 \%)$ which has a 3 day turn around time in our unit.

Initial SDT data from the free standing clinic at the Royal Free Hospital showed an HIV seroprevalence of $3.9 \% .^{3}$ More recently, the yield from this non-GUM based SDT service has fallen to $2 \cdot 0 \%{ }^{4}$ compared with a steady increase in heterosexual HIV seroprevalence identified by anonymous GUM testing and antenatal screening and a minimal reduction in anonymous HIV seroprevalence among homosexual men attending GUM clinics. ${ }^{5}$ These low seroprevalence rates, especially our failure to identify any heterosexual patients may indicate ever greater numbers of the so called "worried well" attending these facilities.

There is a synergistic relation between STDs, particularly genital ulcer disease, and HIV acquisition and transmission. ${ }^{6}$ Hence, we have concerns about the success of treatment and contact tracing for those in whom an STD was identified among Madge et al's cohort. We would suggest that stringent health adviser arrangements are made to ensure compliance with GUM treatment and follow up.

In this low risk cohort our data would also support the view that limited resources may be better targeted elsewhere. The vast majority of the HIV negative attenders were Europe-born people from the London suburbs and the home counties whose health might be better served by accurate information regarding HIV epidemiology and encouragement to utilise comprehensive sexual health services. Both individuals who were identified as HIV positive were in well known risk groups who might well have attended routine screening services. The large demand for HIV SDT has led us to double our capacity. We have demonstrated that such a service can be delivered within the setting of a comprehensive sexual health service, running within a GUM clinic alongside routine clinics, and staffed by existing clinic staff. However, the value of SDT compared with routine testing remains unclear when considering issues such as "cost per case found", behaviour modification and repeat testing after a window period. We are concerned about the value of services such as these, which primarily serve the worried well and whether limited resources would be better spent targeting HIV testing at higher risk groups. However, we would caution against adopting a strategy of only offering selective STD screening within an HIV testing service-it may be best to interpret the need for STD screening within social and geographical dynamics. 
Like others, ${ }^{7}$ we argue that HIV should be seen within the context of sexually transmitted infections in general and that encouraging HIV testing in isolation from other aspects of sexual health will be detrimental to the health of the nation.

N A SMITH

E M CARLIN F C BOAG HIV/GUM Directorate

Chelsea and Westminster Hospital, London

1 Madge S, Elford J, Lipman MCI, Mintz J, Johnson MA. Screening for sexually transmitted diseases in an HIV testing clinic; uptake and prevalence. Genitourin Med 1996;72:347-51.

2 MacKenzie S, Hulme $N$, Lawrence $A$. The incidence of sexually transmitted disease in patients requesting an HIV antibody test. Medical Society for the Study of Venereal Diseases, Zurich, 6-9 May 1993.

3 Squire SB, Elford J, Bor R, Tilsed G, Salt H, Bagdades EK, et al. Open access clinic providing HIV-1 antibody results on day of testing: the first twelve months. $B M F 1991 ; 302$ : 1383-6.

4 Bor R, Lipman M, Elford J, Murray D, Miller $\mathrm{R}$, Griffiths $\mathrm{P}$, et al. HIV seroprevalence in a London same-day testing clinic. AIDS 1994; 8:697-700.

5 Ward H, Hickman $M$. The epidemiology of AIDS and HIV in North West Thames. London: Academic Department of Public Health, St Mary's Medical School, 1994.

6 Wasserheit JN. Epidemiological synergy: interrelationships between human immunodeficiency virus infection and other sexually transmitted diseases. Sex Transm Dis 1992; 19:61-77.

7 Evans B. New clinics for HIV testing: a waste of money? BMF 1993;306:462.

\section{What is normal vaginal flora?}

I am puzzled by the statement that the female genitourinary clinic workers who participated in Priestley and colleagues' study of normal vaginal flora' were anonymised. Althouth names were not used, there is enough information in the published report for at least two individuals, and probably more, to identify themselves. I think that they may also be identifiable to their immediate colleagues if, as is likely, they were known to have taken part in the study.

Perhaps we need greater clarity about the meaning of anonymity, especially in small studies in which individual level data are reported.

\section{HILARY CURTIS \\ Executive Director, $B M A$ Foundation for AIDS, $B M A$ House, Tavistock Square, London WC1H 9 FP}

1 Priestley CJF, Jones BM, Dhar J, Goodwin L. What is normal vaginal flora? Genitourin Med 1997;73:23-8.

\section{Reply}

The authors of the study of normal vaginal flora $^{1}$ (especially the one who herself participated) initially shared the concerns of Hilary Curtis about anonymity, and the design of the study reflected this. Extensive discussion took place among the staff of the clinics while we were recruiting participants, and it transpired that the only concern about the data requested related to the women's perceived infrequency of sexual intercourse in comparison with others.

Identification to colleagues by age range was unlikely in view of the large numbers of staff working in the three centres taking part in the study. Identification by sexual behaviour would not be possible unless an individual had previously discussed said behaviour with colleagues. In fact, several of the participants quite openly discussed their results with other colleagues. Perhaps more importantly, it would not be possible for an outsider to identify any of the participants of the study.

Following completion of the study, individual results were made available by being placed in numbered envelopes for collection; thus in fact all of the participants of the study were able to identify themselves. Finally, after analysis, the results were presented to the clinic staff, and none expressed any reservations about publication of the data; nor have they done so since. Similar concerns about anonymity have previously been raised with regard to case studies; ${ }^{2}$ the important issue is that of consent, and we are confident that all the participants of our study gave informed consent to publication.

CECILIA PRIESTLY

JYOTI DHAR

West Dorset General Hospitals NHS Trust, Department of Genito-Urinary Medicine, Weymouth and District Hospital, Melcombe Avenue,

Weymouth, Dorset DT4 7TB

1 Priestley CJF, Jones BM, Dhar J, Goodwin L. What is normal vaginal flora? Genitourin Med 1997;73:23-8.

2 Smith R. Commentary: The importance of patient's consent for publication. BMf 1996; 313:16.

\section{BOOK REVIEW}

All titles reviewed here are available from the BMf Bookshop, PO Box 295, London WC1H 9TE. Prices include postage in the UK and for members of the British Forces Overseas, but overseas customers should add $15 \%$ to the value of the order for postage and packing. Payment can be made by cheque in sterling drawn on a UK bank, or by credit card (Mastercard, Visa, or American Express) stating card number, expiry date and full name.

Genito-urinary medicine for nurses. By A SUTTON and S PAYNE. (Pp 289; $224 \cdot 50$.) 1996. London: Whurr Publishers. ISBN 1 861560117.

This excellent book edited by Alison Sutton and Stephanie Payne of the Genito-Urinary Nurses Association, and with contributions from nurse practitioners countrywide, is a welcome addition to the genitourinary nursing library. It is an extremely easy book to read, and it will be a useful aid not only to GU nurses, but also to practice, school, community, family planning, and gynaecology nurses.

It provides information on sexually transmitted infections and their management, offers information on cytology, colposcopy and HIV, and briefly outlines the role of the nurse working in these areas. With comprehensive referencing in most chapters, it provides a source of further information for GU nurses wishing to continue their own professional development, while the detailed indexing allows easy access to all the information contained in the book for at a glance reference. The book provides excellent examples of practice including practice statements, which are useful guides for any clinic where they are not yet implemented, and will provide additional information for those clinics currently using them.

While looking at sexually transmitted infections in detail, and providing fascinating insights into the historical aspects of some of the infections, it perhaps does not emphasise sufficiently the "other" side of GUM. With many of our patients presenting with problems other than infection, it would have been useful to have included some paragraphs on the nature of these problems, in particular the role of the nurse in dealing with the psychological trauma that may accompany the often long standing physical problem. For those readers who are not GU nurses, it would also raise awareness of the widening scope of GU medicine.

With the advent of diploma and degree programmes in sexual health, it might also be beneficial if in future editions of the book, some mention of nursing research, reflective in practice, management, and a little more detail on clinical supervision and microscopy relating to GU nursing were to be made. Also with our specialty so heavily entrenched in attitudes and prejudice, perhaps a little more space could have been allocated to the nurse/patient relationship, in particular the part the nurse plays in assisting patients to cope positively with their visit/diagnosis.

The personal experience of all authors contributing to this book clearly illustrates the widely differing role of the nurse in genitourinary medicine, and provides a wealth of experience that will be of great benefit to all readers whether in the GU setting or elsewhere. It is a book to be highly recommended to all departments of genitourinary medicine, and to nurses in other specialties who recognise the need to improve their knowledge of the wider issues of sexually transmitted infections.

ANGELA CARPENTER

18th Annual Congress of the European
Society of Mycobacteriology (ESM-97), 17-18 June 1997, Cordoba, Spain

Further details: Congress Secretariat of 을 ESM-97 and ISM-97, Vincit International $N$ Agency, Plaza de Espana noLIST18, Toree de Madrid, Planta no10, 28008 Madrid, Spain. Tel 34-1-5590426; Fax 34-15592505 .

3rd International Conference on AIDS Impact-Biopsychosocial Aspects of HIV Infection, 22-25 June 1997, Melbourne, Australia

Further details: Conference Secretariat, AIDS Impact, the Meeting Planners, 108 Church Street, Hawthorn, Victoria, Australia 3122. Tel +61-3-9819-3700; Fax +61-3-9819-5978.

37th General Assembly, IUVDT, in conjunction with Asia Pacific Branch, IUVDT, Melbourne, 25-28 June 1997

Further details: The Meeting Planners, Australia. Tel: +613 9819 3700; Fax: +613 98195978 .

20th International Congress of Chemotherapy (ICC)-Sydney, 29 June-4 July 1997 